\title{
Germinação e formação de mudas enxertadas de gravioleira sob estresse salino(1)
}

\author{
Reginaldo Gomes Nobre(2), Pedro Dantas Fernandes ${ }^{(2)}$, Hans Raj Gheyi(2), Francisco José de Seixas Santos ${ }^{(3)}$, \\ Idelfonso Leandro Bezerra ${ }^{(2)}$ e Marcelo Tavares Gurgel(2)
}

\begin{abstract}
Resumo - A expansão da fruticultura no Nordeste brasileiro pode sofrer limitações, já que algumas áreas com elevado potencial de cultivo são abastecidas por água de qualidade insatisfatória. Considerando a potencialidade de cultivo da gravioleira (Annona muricata L.) na região e o fato de não existir dados sobre a produção de mudas enxertadas dessa espécie, sob estresse salino, conduziu-se este trabalho com o objetivo de avaliar os efeitos da salinidade da água de irrigação sobre o tipo 'Crioula' tendo 'Morada' como porta-enxerto. A água de irrigação de condutividade elétrica entre 0,5 e 5,5 dS m' foi preparada mantendo-se proporção equivalente a 7:2:1, entre $\mathrm{Na}: \mathrm{Ca}: \mathrm{Mg}$, respectivamente; o delineamento foi em blocos casualizados, com quatro repetições, 54 plantas por parcela. Foram avaliados: germinação, formação do porta-enxerto (número de folhas, altura de plantas, diâmetro do caule, matéria seca de parte aérea e de raiz, área foliar e número de plantas aptas à enxertia) e número de enxertos vivos. A porcentagem de germinação da gravioleira não foi afetada pelo estresse salino, porém a velocidade de emergência e o acúmulo de fitomassa foram reduzidos com aumento da salinidade da água de irrigação. Pode-se usar água com até $1,5 \mathrm{dS} \mathrm{m}^{-1}$ de condutividade elétrica na formação de mudas de graviola.
\end{abstract}

Termos para indexação: Annona muricata, salinidade, condutividade elétrica, água de irrigação.

\section{Germination and formation of grafted seedlings of soursop under saline stress}

\begin{abstract}
The expansion of fruit cultivation in Northeast Brazil may sometimes be restricted because areas of high potential are supplied with poor quality water. Considering the potential of soursop (Annona muricata L.) cultivation in the region and the inexistence of data on grafted seedlings of this specie under saline stress, this study was conducted to evaluate effects of irrigation water salinity on 'Crioula' type as the scion and 'Morada' as the rootstock. The irrigation water with electrical conductivity varying from 0.5 to $5.5 \mathrm{dS} \mathrm{m}^{-1}$ was prepared maintaining the equivalent proportion of 7:2:1 among $\mathrm{Na}: \mathrm{Ca}: \mathrm{Mg}$, respectively; a completely randomized block design was used, with four replications and 54 plants per plot. The variables appraised were: germination, formation of rootstock (number of leaves, plant height, stem diameter, shoot and root dry matter, leaf area and number of graftable plants) and the number of alive grafts. The percentage of germination was not affected by salinity but the velocity of emergence and accumulation of dry matter reduced with the increase in salinity of irrigation water. In seedling formation, water with salinity up to $1.5 \mathrm{dS} \mathrm{m}^{-1}$ of electrical conductivity may be used.
\end{abstract}

Index terms: Annona muricata, salinity, electrical conductivity, irrigation water.

(1) Aceito para publicação em 2 de setembro de 2003.

(2) Universidade Federal de Campina Grande, Centro de Ciências e Tecnologia, Dep. de Engenharia Agrícola, Caixa Postal 10087, CEP 58109-970 Campina Grande, PB. E-mail: reginobr@bol.com.br, pdantas@deag.ufcg.edu.br, hans@deag.ufcg.edu.br,idelfonsolb@bol.com.br, mtgurgel@bol.com.br

(3) Embrapa-Centro de Pesquisa Agropecuária do Meio-Norte, Caixa Postal 341, CEP 64200-970 Parnaíba, PI. E-mail: seixas@cpamn.embrapa.br

\section{Introdução}

A gravioleira (Annona muricata L.) é uma planta tropical originária da América Central e dos Vales Peruanos. Atualmente, destaca-se como fruteira na região semi-árida do Nordeste brasileiro, onde encontra condições ótimas de clima e solo para o seu desenvolvimento (Araújo Filho et al., 1998).

Apesar da expansão da área cultivada, o Brasil ainda importa graviola de países como África do Sul 
e Venezuela. O interesse por essa anonácea vem aumentando em nosso país, pela grande aceitação do mercado e pela crescente demanda das indústrias de fabricação de polpas, sucos, sorvetes e geléias. Entretanto, segundo Araújo Filho et al. (1998), são baixos os rendimentos de frutos $\left(2.000 \mathrm{~kg} \mathrm{ha}^{-1}\right)$, pelo pouco uso de técnicas adequadas ao seu cultivo.

A irrigação é uma das mais importantes práticas para se obter maior produtividade e melhor qualidade de frutos. A qualidade da água a ser utilizada na irrigação deve ser levada em consideração, pois é um dos fatores que tem reduzido ou impossibilitado a expansão da fruticultura no Nordeste brasileiro. Associado a isso, nessa região é alta a taxa de evapotranspiração e insuficiente a pluviosidade para uma lavagem adequada dos sais, favorecendo a salinização dos solos irrigados (Medeiros, 1992).

Segundo Rhoades et al. (1992) e Steppuhn (2001), a disponibilidade de água para irrigação pode ser aumentada por meio de criterioso uso de águas salinas e reciclagem de águas de drenagem; águas atualmente consideradas como inadequadas para a irrigação podem ser utilizadas, sem maiores conseqüências em longo prazo para culturas e solos, desde que sejam adotadas práticas de manejo culturais adequadas e culturas tolerantes à salinidade.

O conhecimento do teor médio de sais na zona radicular, tolerável pelas plantas, sem afetar significativamente seus rendimentos, pode favorecer a utilização de águas com certo grau de salinidade, tão comuns no Nordeste brasileiro. Nesse sentido devem ser realizados estudos visando à obtenção de índices de tolerância das culturas à salinidade, propiciando o estabelecimento do grau de restrição das águas para irrigação (Steppuhn, 2001).

Poucos autores estudaram efeitos do estresse salino em gravioleira (Oliveira, 1991; Silva, 1997; Santos, 2000) e nenhum trabalho se prolongou até a formação de mudas enxertadas, aptas ao transplante para o campo.

O objetivo deste trabalho foi avaliar o efeito da salinidade da água de irrigação na formação de mudas de gravioleira (Annona muricata L.), abrangendo fases anteriores e posteriores à enxertia.

\section{Material e Métodos}

O experimento foi realizado no viveiro da EmbrapaCentro Nacional de Pesquisa de Agroindústria Tropical (CNPAT), no Município de Pacajus, CE, de janeiro a julho de 2001.

Foram avaliados seis níveis de condutividade elétrica (CE) da água de irrigação $\left(0,5,1,5,2,5,3,5,4,5\right.$ e 5,5 dS m $\left.{ }^{-1}\right)$ na formação de mudas de gravioleira. $\mathrm{O}$ delineamento estatístico utilizado foi em blocos casualizados com quatro repetições, totalizando 24 parcelas experimentais, cada uma composta de 54 plantas.

Os recipientes utilizados foram tubetes de plástico (19 $\mathrm{cm}$ de altura e 6,3 cm de diâmetro), com uma capacidade de $288 \mathrm{~cm}^{3}$, perfurados na parte inferior para permitir a livre drenagem; os tubetes foram suspensos em bandejas apropriadas, cada uma com capacidade de 54 tubetes, instaladas sobre estruturas metálicas a $0,8 \mathrm{~m}$ de altura.

No enchimento dos tubetes foi utilizado substrato composto de uma mistura de casca de arroz carbonizada, húmus de minhoca e palha de carnaúba, respectivamente, na proporção de 2:1:1 (base volume), comumente utilizado para a produção de mudas de graviola pela Embrapa-CNPAT (Araújo Filho et al., 1998). Os dados da análise química do substrato, obtidos conforme métodos recomendados pela Embrapa (1997), podem ser observados na Tabela 1.

As águas de irrigação foram preparadas mediante adição de solução $1 \mathrm{~N}$ de $\mathrm{NaCl}, \mathrm{CaCl}_{2} \cdot 2 \mathrm{H}_{2} \mathrm{O}$ e $\mathrm{MgCl}_{2} \cdot 6 \mathrm{H}_{2} \mathrm{O}$ à água proveniente de um poço tubular, de forma a se obter a CE de cada tratamento, com proporção equivalente de 7:2:1 entre $\mathrm{Na}: \mathrm{Ca}: \mathrm{Mg}$, relação esta predominante nas principais fontes de água, disponíveis para irrigação no Nordeste brasileiro, conforme Medeiros (1992). No preparo das águas de irrigação foi utilizada a relação entre

Tabela 1. Características químicas do substrato utilizado na formação de mudas de gravioleira.

\begin{tabular}{lr}
\hline Características & Valor \\
\hline $\mathrm{Ca}\left(\mathrm{mmolc} \mathrm{dm}^{-3}\right)$ & 88,86 \\
$\mathrm{Mg}\left(\mathrm{mmolc} \mathrm{dm}^{-3}\right)$ & 40,84 \\
$\mathrm{Na}\left(\mathrm{mmol} \mathrm{dm}^{-3}\right)$ & 130,00 \\
$\mathrm{~K}\left(\mathrm{mmolc} \mathrm{dm}^{-3}\right)$ & 34,00 \\
$\mathrm{H}+\mathrm{Al}\left(\mathrm{mmok} \mathrm{dm}^{-3}\right)$ & 26,00 \\
$\mathrm{CTC}\left(\mathrm{mmolc} \mathrm{dm}^{-3}\right)$ & 319,70 \\
$\mathrm{~V}(\%)$ & 91,87 \\
Matéria orgânica $\left(\mathrm{g} \mathrm{dm}^{-3}\right)$ & 215,40 \\
$\mathrm{P}($ resina $)\left(\mathrm{mg} \mathrm{dm}^{-3}\right)$ & 48,87 \\
Mn $\left(\mathrm{mg} \mathrm{dm}^{-3}\right)$ & 16,50 \\
$\mathrm{Zn}\left(\mathrm{mg} \mathrm{dm}^{-3}\right)$ & 15,08 \\
$\mathrm{Cu}\left(\mathrm{mg} \mathrm{dm}^{-3}\right)$ & 4,41 \\
Fe $(\mathrm{mg} \mathrm{dm})$ & 19,20 \\
$\mathrm{pH}$ em água $(1: 2,5)$ & 5,75 \\
Condutividade elétrica extrato de saturacão $\left(\mathrm{dS} \mathrm{m}^{-1}\right)$ & 5,30 \\
\hline
\end{tabular}


condutividade elétrica e concentração de sais $\left(\mathrm{mmol}_{\mathrm{c}} \mathrm{L}^{-1}=10 \mathrm{CE}\right)$, extraída de Rhoades et al. (1992).

O substrato, já no tubete, recebeu lavagens com $2 \mathrm{~L}$ de água do respectivo tratamento, por bandeja, em cada aplicação, de forma a se obter uma condutividade elétrica da água de drenagem próxima a do respectivo tratamento.

$\mathrm{Na}$ formação do porta-enxerto foram utilizadas sementes do tipo Morada, obtidas no campo experimental de Pacajus da Embrapa-CNPAT, de formato e tamanho típicos da espécie, sem sinais de pragas ou doenças. As sementes foram submetidas a um tratamento de quebra de dormência, com imersão em vinagre de álcool por 15 minutos e, depois, foram semeadas três por tubete, na posição vertical e profundidade de $2 \mathrm{~cm}$, com o hilo voltado para baixo (Santos, 2000).

Irrigou-se diariamente ao final de cada tarde, com volume de água que proporcionasse, aproximadamente, $40 \%$ de drenagem até à fase de enxertia e 50\% após a enxertia, visando evitar acumulação excessiva de sais no substrato.

Adubações foliares foram realizadas, quinzenalmente, a partir do 15 dia após o semeio, com ubifol (N - 15\%, $\mathrm{P}_{2} \mathrm{O}_{5}-15 \%, \mathrm{~K}_{2} \mathrm{O}-20 \%, \mathrm{Ca}-1,5 \%, \mathrm{Mg}-0,05 \%$, $\mathrm{Zn}-0,20 \%, \mathrm{~B}-0,05 \%, \mathrm{Fe}-0,10 \%, \mathrm{Mn}-0,02 \%$, $\mathrm{Cu}-0,05 \%$, Mo - 0,01\% e S - 3\%) + nitrocálcio (N-22\% e Ca-7\%) na proporção de $1 \mathrm{~mL}$ do adubo para $1 \mathrm{~L}$ de água, aplicando-se $400 \mathrm{~mL}$ por bandeja; foram, igualmente, adotados os cuidados fitossanitários necessários à formação de mudas de graviola.

A germinação foi avaliada mediante contagem diária do número de plântulas emergidas, usando-se como critério o surgimento do epicótilo na superfície do tubete. Realizouse o desbaste aos 35 dias após emergência (DAE) da primeira plântula, deixando-se a de melhor crescimento por tubete. Nessa mesma data avaliaram-se a porcentagem de germinação (número de sementes emergidas em relação ao número das semeadas) e o índice de velocidade de emergência (IVE), conforme Vieira \& Carvalho (1994):

IVE $=\frac{E_{1}}{N_{1}}+\frac{E_{2}}{N_{2}}+\ldots+\frac{E_{n}}{N_{n}}$

em que, $E_{1}, E_{2}, \ldots E_{n}$ são os números de plântulas emergidas, computadas na primeira, segunda e última contagem e $\mathrm{N}_{1}$, $\mathrm{N}_{2}, \ldots \mathrm{N}_{\mathrm{n}}$ são os números de dias da semeadura à primeira, segunda e última contagem, respectivamente.

A avaliação do crescimento e desenvolvimento do porta-enxerto foi efetuada aos 40, 65 e 80 DAE, utilizando-se 20 plantas centrais por parcela (bandeja), com base nas variáveis número de folhas, altura da planta e diâmetro do caule; aos 40 e 80 DAE foram avaliadas a área foliar e massas da parte aérea e da raiz. Aos 80 DAE houve avaliação do número de plantas aptas à enxertia (PAE) e foi feita garfagem nos porta-enxertos com diâmetro mínimo do caule de $0,5 \mathrm{~cm}$, usando-se como enxerto garfos do tipo 'Crioula'. Aos 25 e 50 dias após a enxertia (DEX) determinou-se o número de enxertos brotados (NEB), considerando-se como tais aqueles com pelo menos uma brotação do garfo. Foi considerado o limite de 50 DEX por ser o recomendado para início de comercialização das mudas.

Os dados foram submetidos à análise de variância simples e teste $F(p<0,01$ e $p<0,05)$, sendo os valores de PAE e NEB transformados em $(x+0,5)^{0,5}$, seguindo-se recomendações de Ferreira (2000); os graus de liberdade relativos à salinidade foram desdobrados em componentes de regressão.

\section{Resultados e Discussão}

\section{Porta-enxerto}

A salinidade da água de irrigação não afetou a porcentagem de germinação aos $35 \mathrm{DAE}$, mas o índice de velocidade de emergência (IVE) foi reduzido, significativamente $(\mathrm{p}<0,01)$, pela condutividade elétrica da água de irrigação (CE), evidenciando que a adição de sais retarda a emergência das plântulas (Tabela 2). As sementes de gravioleira germinaram acima de $73,6 \%$, em todos os níveis de salinidade, superando os 51,4\% obtidos por Silva (1997) e 56,2\% encontrados por Santos (2000). Segundo Pinto \& Silva (1995), baixos índices de germinação são justificados em gravioleira pela perda natural do poder germinativo por causa do fenômeno de semente recalcitrante, normalmente observada nessa espécie.

Aos 35 DAE houve decréscimo médio de 4,3\%, por aumento unitário da salinidade da água de irriga-

Tabela 2. Porcentagem de germinação (PG) da gravioleira e índice de velocidade de emergência (IVE) aos 35 dias após a emergência da primeira plântula, sob diferentes níveis de salinidade (S) da água de irrigação medida pela condutividade elétrica da água (CE).

\begin{tabular}{|c|c|c|}
\hline $\mathrm{CE}$ & PG (\%) & IVE \\
\hline $\mathrm{S}_{1}\left(0,50 \mathrm{dS} \mathrm{m}_{1}^{-1}\right)$ & 76,27 & 4,54 \\
\hline $\mathrm{S}_{2}\left(1,50 \mathrm{dS} \mathrm{m}^{-1}\right)$ & 79,02 & 4,67 \\
\hline $\mathrm{S}^{3}\left(2,50 \mathrm{dS} \mathrm{m}^{-1}\right)$ & 77,16 & 4,46 \\
\hline $\mathrm{S}_{4}\left(3,50 \mathrm{dS} \mathrm{m}^{-1}\right)$ & 75,51 & 4,17 \\
\hline $\mathrm{S}_{5}\left(4,50 \mathrm{dS} \mathrm{m}_{-1}^{-1}\right)$ & 74,85 & 3,83 \\
\hline $\mathrm{S}_{6}\left(5,50 \mathrm{dS} \mathrm{m}^{-1}\right)$ & 73,61 & 3,68 \\
\hline
\end{tabular}


ção, na velocidade de emergência das plântulas, em relação à testemunha $\left(\mathrm{S}_{1}-0,5 \mathrm{dS} \mathrm{m}^{-1}\right)($ Tabela 2$)$. Estes resultados podem ser explicados pelo fato de os sais presentes na água de irrigação reduzirem o potencial osmótico da solução do solo, resultando em retardamento do tempo de embebição das sementes e, conseqüentemente, da emergência das plântulas (Ashraf \& Iram, 2002). Silva (1997), trabalhando com gravioleira, obteve resultados semelhantes.

Os níveis de salinidade da água de irrigação afetaram, significativamente $(\mathrm{p}<0,01)$, o número de folhas (NF), altura de plantas (AP) e diâmetro de caule (DC) nas três épocas de avaliação (Figura 1). Segundo os modelos matemáticos obtidos, o efeito da salinidade foi linear para NF e DC e quadrático para AP e se intensificou ao longo do desenvolvimento das plantas. Os decréscimos relativos por aumento unitário da $\mathrm{CE}$, aos 40, 65 e $80 \mathrm{DAE}$, em relação a $\mathrm{S}_{1}$, foram respectivamente de $9,3 \%, 13,2 \%$ e $15,5 \%$ para $\mathrm{NF}$ e de 5,9, 8,9 e 9,8\% para DC; nessas mesmas épocas, os decréscimos relativos de AP, entre $\mathrm{S}_{1}$ e $\mathrm{S}_{6}$, foram de 40,4, 58,3 e 58,7\%, respectivamente. Esses resultados evidenciam que a intensidade aumentou no período compreendido entre 40 e $65 \mathrm{DAE}$, mais do que entre 65 e $80 \mathrm{DAE}$, indicando uma adaptação das plantas ao estresse salino, ao longo do tempo. Conforme Chartzoulakis \& Klapaki (2000), o aumento da salinidade no substrato reduz a absorção de água pelas raízes, inibindo a atividade meristemática e o alongamento celular, tendo como conseqüência a redução no crescimento e desenvolvimento da cultura.

Comparando-se os efeitos negativos da salinidade em NF, AP e DC, em termos relativos, NF foi o mais afetado, o que está de acordo com observações de Koyro (2000), segundo o qual a redução do tamanho e do número de folhas destaca-se entre as mudanças morfológicas, em condições de estresse salino. Silva (1997) e Santos (2000) também observaram decréscimo na emissão foliar em gravioleira, com aumento do nível de salinidade.

Na comparação dos resultados de AP e DC obtidos, com os encontrados por Santos (2000), para formação de mudas de gravioleira tipo Morada, em sacos de polietileno e substrato de solo + esterco, constata-se que as plantas se desenvolvem melhor em tubetes, em função de drenagem mais eficiente.
A salinidade afetou significativamente $(\mathrm{p}<0,01)$ a produção de fitomassa aos 40 e 80 DAE das plântulas. Conforme estudos de regressão para massa da matéria seca da parte aérea (Figura 2), o efeito da salinidade foi linear aos 40 DAE e quadrático aos 80 DAE, denotando-se ter ocorrido, com o passar dos dias, recuperação das plantas na formação de fitomassa, nos níveis mais baixos de CE; ocorreram reduções, em relação a $S_{1}$, de 15,4 e 63,8\% aos 40 DAE e de 29,5 e $92,5 \%$ aos 80 DAE, para os níveis $S_{2}$ e $S_{6}$, respectivamente. Em raízes, os efeitos da salinidade foram lineares (Figura 2), proporcionando decréscimos re-
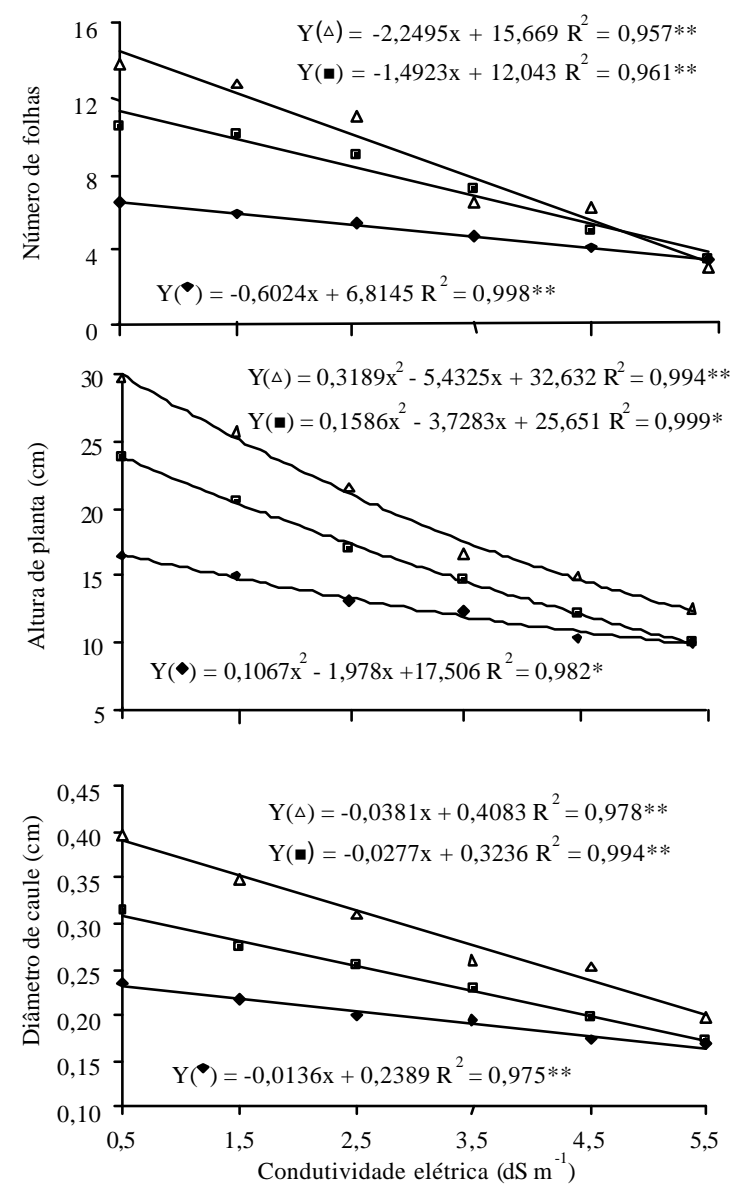

Figura 1. Número de folhas, altura de planta e diâmetro do caule da gravioleira, aos $40(\Delta), 65(\square)$ e $80(\Delta)$ dias após a emergência (DAE) da primeira plântula, em razão da salinidade da água de irrigação, medida pela condutividade elétrica. 
lativos de 11,6 e 15,9\%, por aumento unitário de CE, em relação a $S_{1}$, aos 40 e 80 DAE, respectivamente. À medida que houve incremento dos níveis salinos, ao longo do tempo ocorreram reduções bastante acentuadas na produção de fitomassa da planta, denotando mais uma vez, a sensibilidade da cultura. No entanto, com base nos dados de regressão, notase que a salinidade inibiu menos o crescimento radicular do que o da parte aérea, nas duas épocas analisadas, o que pode ser explicado pela necessidade que tem a planta de garantir uma maior superfície
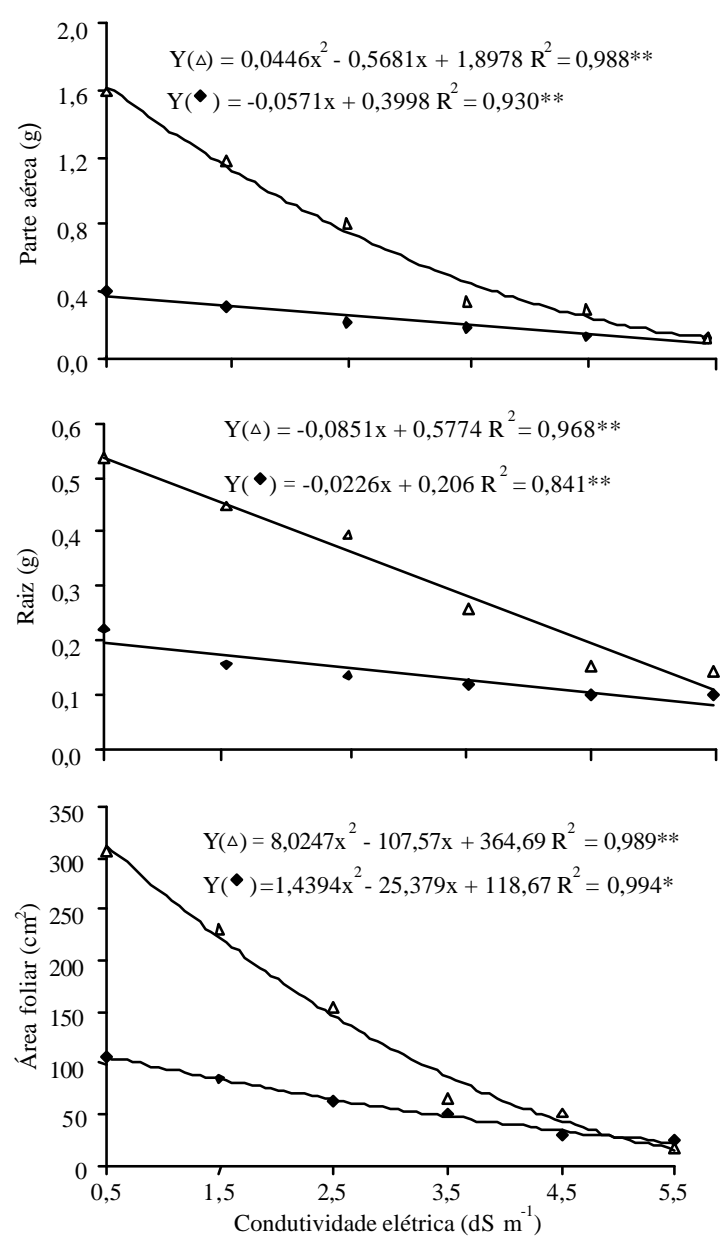

Figura 2. Massa da matéria seca da parte aérea e da raiz e área foliar da gravioleira, aos $40(\diamond)$ e $80(\Delta)$ dias após a emergência da primeira plântula, em razão da salinidade da água de irrigação, medida pela condutividade elétrica. radicular para absorção de água, devido ao abaixamento do potencial osmótico da solução do solo. Alguns autores trabalhando com espécies diferentes, relatam maior sensibilidade da parte aérea em condições de estresse salino: algodoeiro (Meloni et al., 2001) e salvadora (Ramoliya \& Pandey, 2002). Outros autores indicam ser mais sensível o sistema radicular: abacaxizeiro (Marinho et al., 1998) e alho (Amorim et al., 2002), possivelmente devido à constituição genética.

A salinidade afetou, igualmente, a área foliar (Figura 2), com efeito quadrático $(\mathrm{p}<0,01)$ e decrescente em ambas as avaliações. Entre 40 e 80 DAE houve aumento apreciável da área foliar nas gravioleiras sob níveis mais baixos de salinidade (até $2,5 \mathrm{dS} \mathrm{m}^{-1}$ ), em proporções superiores a $100 \%$; de forma semelhante ao ocorrido com a massa da parte aérea seca, a partir de 3,5 dS m-1 intensificaram-se os efeitos da salinidade, com redução drástica da superfície foliar das plantas. Segundo as respectivas equações de regressão, no nível $\mathrm{S}_{6}$ ocorreram reduções de 78,7 e $94,9 \%$ aos 40 e 80 DAE, respectivamente, em relação a $S_{1}$.

O decréscimo da área foliar provavelmente decorre da diminuição do volume de células e, segundo Mittova et al. (2002) e Sultana et al. (2002), as reduções de área foliar e de fotossíntese contribuem, de certo modo, para adaptação da cultura à salinidade. A redução da área foliar sob estresse hídrico pode ser um mecanismo de sobrevivência que permite a conservação de água, pela menor área transpiratória das plantas.

\section{Enxerto}

A salinidade afetou, significativamente $(\mathrm{p}<0,01)$, o número de plantas aptas à enxertia (PAE), aos 80 DAE, com efeitos mais pronunciados a partir de CE igual a 2,5 dS m${ }^{-1}$, resultando numa redução de 41,3\% (Tabela 3). No nível mais alto de salinidade estudado $\left(5,5 \mathrm{dS} \mathrm{m}^{-1}\right)$ houve redução de $97,2 \% \mathrm{em}$ PAE, evidenciando a elevada sensibilidade ao estresse salino da combinação envolvendo 'Morada' (porta-enxerto) e 'Crioula' (enxerto). Não se encontram resultados de pesquisa que avaliem os efeitos da salinidade na fase de enxertia de mudas de gravioleira. No entanto, em cajueiro-anão-precoce, 
Meireles (1999) observou redução significativa do número de plantas em condições de serem enxertadas, quando o nível de $\mathrm{CE}$ era de $2,63 \mathrm{dS} \mathrm{m}^{-1}$.

$\mathrm{O}$ estresse salino também afetou a taxa de pegamento da enxertia, reduzindo significativamente $(\mathrm{p}<0,01)$ o número de enxertos brotados (NEB) a partir do nível $\mathrm{S}_{3}$ (Tabela 3 ). Quanto à sobrevivência dos enxertos, entre os componentes de regressão em que foram desdobrados os efeitos do fator salinidade (Tabela 3), optou-se pelo modelo linear por ser o mais adequado à interpretação dos resultados, por não haver mudança na linha de tendência quando aumenta a CE. Em relação a $\mathrm{S}_{1}$, o NEB diminuiu 17,4 e $20,3 \%$ por aumento unitário da CE, respectivamente, aos 25 e 50 dias após a enxertia.

Até o nível $\mathrm{S}_{2}\left(1,5 \mathrm{dS} \mathrm{m}^{-1}\right)$ não houve influência da salinidade sobre essa variável, ocorrendo, ao contrário, aumento do número de enxertos com brotação, entre o 25 e o 50 ia após enxertia. Com incremento da salinidade da água de irrigação e aumento do tempo de exposição das plantas aos níveis salinos, ocorreu morte de todas as mudas submetidas a níveis iguais ou superiores a $3,5 \mathrm{dS} \mathrm{m} \mathrm{m}^{-1}$, o que indica grande sensibilidade da gravioleira ao estresse salino, principalmente a partir da fase de enxertia. Com a união de tecidos de plantas diferentes na enxertia, pode ocorrer aumento da sensibilidade da gravioleira aos níveis mais altos de salinidade. Estudos sobre a distribuição dos íons absorvidos em órgãos de porta-enxerto e enxerto, principalmente em regiões próximas ao enxerto, poderiam contribuir para uma melhor

Tabela 3. Número de plantas aptas à enxertia (PAE) aos 80 dias após a emergência da primeira plântula, número de enxertos brotados (NEB) aos 25 e 50 dias após a enxertia e as respectivas equações de regressão significativas, em razão dos níveis de salinidade da água de irrigação, medida pela condutividade elétrica da água (CE).

\begin{tabular}{|c|c|c|c|}
\hline \multirow[t]{2}{*}{$\mathrm{CE}$} & \multirow[t]{2}{*}{$\mathrm{PAE}^{(1)}$} & \multicolumn{2}{|c|}{$\mathrm{NEB}^{(1)}$} \\
\hline & & 25 dias & 50 dias \\
\hline S $1(0$ & 6,73 & 4,60 & 5,04 \\
\hline $\mathrm{S}_{2}\left(1,50 \mathrm{dS} \mathrm{m}^{-1}\right)$ & $6,58(42,75)$ & 4,41 (19) & $5,15(26,0)$ \\
\hline $\mathrm{S}^{3}\left(2,50 \mathrm{dS} \mathrm{m}^{-1}\right)$ & $5,15(26,25)$ & 3,67 (13) & $3,31(10,7)$ \\
\hline $\mathrm{S}_{4}\left(3,50 \mathrm{dS} \mathrm{m}^{-1}\right)$ & $3,85(14,50)$ & $1,84(3)$ & $0,71(0,0)$ \\
\hline $\mathrm{S}_{5}\left(4,50 \mathrm{dS} \mathrm{m}_{-1}^{-1}\right)$ & $2,39(5,25)$ & $1,56(2)$ & $0,71(0,0)$ \\
\hline $\mathrm{S}_{6}\left(5,50 \mathrm{dS} \mathrm{m}^{-1}\right)$ & $1,22(1,25)$ & $0,71(0)$ & $0,71(0,0)$ \\
\hline \multicolumn{4}{|c|}{$\begin{array}{l}\text { YPAE }=0,0641 x^{3}-0,6703 x^{2}+0,785 x+6,5375\left(R^{2}=0,998^{* *}\right) ; x=C E \\
Y(N E B 25 \text { DEX })=-0,8523 x+5,3552\left(R_{2}^{2}=0,948^{* *}\right) ; x=C E \\
Y(N E B 50 \text { DEX })=-1,0734 x+5,8253\left(R^{2}=0,875^{* *}\right) ; x=C E\end{array}$} \\
\hline
\end{tabular}

${ }^{(1)}$ Dados transformados em $(x+0,5)^{0,5}$; dados originais entre parênteses compreensão desse fenômeno. Em dois clones de cajueiro (CCP06 e CCP1001), Bezerra et al. (2002) registraram maior sensibilidade à concentração de sais, após enxertia por garfagem, com perda total das mudas a partir de 3,5 dS m-1. Meireles (1999), enxertando cajueiro-anão-precoce CCP76 por borbulhia, verificou redução de pegamento de 79,2\% quando foi usada água com $0,26 \mathrm{dS} \mathrm{m}^{-1}$ para apenas $1,0 \%$ com água de $2,63 \mathrm{dS} \mathrm{m}^{-1}$.

\section{Conclusões}

1. Níveis de salinidade de até $5,5 \mathrm{dS} \mathrm{m}^{-1}$ na água de irrigação não afetam a germinação de sementes de gravioleira Morada, mas níveis a partir de 2,5 dS m ${ }^{1}$ diminuem significativamente a sua velocidade de emergência.

2. O acúmulo de fitomassa na parte aérea e no sistema radicular do porta-enxerto Morada decresce com o incremento da salinidade da água de irrigação.

3. Pode-se usar água com até $1,5 \mathrm{dS} \mathrm{m}^{-1} \mathrm{de}$ condutividade elétrica na produção de mudas enxertadas do tipo 'Crioula' de graviola.

4. A sobrevivência dos enxertos diminui com o aumento da salinidade e com o tempo de exposição das plantas ao estresse salino, ocorrendo morte de todas as plantas submetidas à salinidade superior a $2,5 \mathrm{dS} \mathrm{m}^{-1}$.

\section{Referências}

AMORIM, J. R. A.; FERNANDES, P. D.; GHEYI, H. R.; AZEVEDO, N. C. Efeito da salinidade e modo de aplicação da água de irrigação no crescimento e produção de alho. Pesquisa Agropecuária Brasileira, Brasília, v. 37, n. 2, p. 167-176, fev. 2002.

ARAÚJO FILHO, G. C.; ANDRADE, O. M. S.; CASTRO, F. de A.; SÁ, F. T. Instruções técnicas para o cultivo da gravioleira. Fortaleza: Embrapa-CNPAT, 1998. 20 p. (Instruções Técnicas, 2).

ASHRAF, M.; IRAM, A. Optimization and influence of seed priming with salts of potassium or calcium in two spring wheat cultivars differing in salt tolerance, at the initial growth stages. Agrochimica, Pisa, v. 46, n. 1/2, p. 47-55, 2002.

BEZERRA, I. L.; GHEYI, H. R.; FERNANDES, P. D.; SANTOS, F. J. S.; GURGEL, M. T.; NOBRE, R. G. Ger- 
minação, formação de porta-enxertos e enxertia de cajueiro anão-precoce, sob estresse salino. Revista Brasileira de Engenharia Agrícola e Ambiental, Campina Grande, v. 6, n. 3, p. 420-424, 2002.

CHARTZOULAKIS, K.; KLAPAKI, G. Response of two greenhouse pepper hybrids to $\mathrm{NaCl}$ salinity during different growth stages. Scientia Horticulturae, Amsterdam, v. 86, n. 3, p. 247-260, 2000.

EMBRAPA. Centro Nacional de Pesquisa de Solos (Rio de Janeiro, RJ). Manual de métodos de análise de solo. Rio de Janeiro, 1997. 297 p.

FERREIRA, P. V. Estatística experimental aplicada à agronomia. Maceió: Ufal/Edufal/Fundepes, 2000. 437 p.

KOYRO, H. M. Effect of high NaCl-salinity on plant growth, leaf morphology, and ion composition in leaf tissues of Beta vulgaris ssp. maritime. Journal of Applied Botany, Berlin, v. 74, n. 1/2, p. 67-73, 2000.

MARINHO, F. J. L.; FERNANDES, P. D.; GHEYI, H. R Desenvolvimento de mudas de abacaxizeiro, cv. Smooth Cayenne, sob diferentes condições de salinidade da água de irrigação. Revista Brasileira de Engenharia Agrícola e Ambiental, Campina Grande, v. 2, n. 1, p. 1-5, 1998

MEDEIROS, J. F. de. Qualidade da água de irrigação e evolução da salinidade nas propriedades assistidas pelo “GAT” nos Estados do RN, PB e CE. 1992. 173 f. Dissertação (Mestrado em Engenharia Agrícola) - Universidade Federal da Paraíba, Campina Grande, 1992.

MEIRELES, A. C. M. Salinidade da água de irrigação e desenvolvimento de mudas de cajueiro anão-precoce (Anacardium occidentale L.). 1999. 60 f. Dissertação (Mestrado em Irrigação e Drenagem) - Universidade Federal do Ceará, Fortaleza, 1999.

MELONI, D. A.; OLIVA, M. A.; RUIZ, H. A.; MARTINEZ, C. A. Contribution of proline and inorganic solutes to osmotic adjustment in cotton under salt stress. Journal of Plant Nutrition, New York, v. 24, n. 3, p. 599612, 2001.

MITTOVA, V.; TAL, M.; VOLOKITA, M.; GUY, M. Salt stress induces up-regulation of an efficient chloroplast antioxidant system in the salt-tolerant wild tomato species but not in the cultivated species. Physiologia Plantarum, Copenhagen, v. 115, n. 3, p. 393-400, 2002.

OLIVEIRA, E. M. de. Efeito da salinidade no desenvolvimento da gravioleira (Annona muricata L.). 1991 39 f. Monografia (Graduação em Agronomia) - Universidade Federal da Paraíba, Areia, 1991.

PINTO, A. C. de Q.; SILVA, E. M. de. A cultura da gravioleira. Brasília: Embrapa-SPI, 1995. 106 p. (Série de Publicações Técnicas FRUPEX, 7).

RAMOLIYA, P. J.; PANDEY, A. N. Effect of increasing salt concentration on emergence, growth and survival of seedlings of Salvadora oleoides. Journal of Arid Environments, London, v. 51, n. 1, p. 121-132, 2002.

RHOADES, J. D.; KANDIAH, A.; MASHALI, A. M. The use of saline waters for crop production. Rome: FAO, 1992. 133 p. (Irrigation and Drainage Paper, 48).

SANTOS, F. J. de S. Produção de mudas de pé franco de graviola (Annona muricata L.) irrigadas com água de diferentes qualidades. In: CONGRESSO BRASILEIRO DE ENGENHARIA AGRÍCOLA, 29., 2000, Fortaleza. Anais... Fortaleza: Sociedade Brasileira de Engenharia Agrícola/UFC, 2000. p. 166-168.

SILVA, D. A. Efeitos de fontes e níveis de salinidade sobre a germinação e desenvolvimento de plântulas de graviola (Annona muricata L.). 1997. 64 f. Dissertação (Mestrado em Manejo de Solos) - Universidade Federal da Paraíba, Areia, 1997.

STEPPUHN, H. Pre-irrigation of a severely-saline soil with in situ water to establish dry land forages. Transactions of the ASAE, St. Joseph, v. 44, n. 6, p. 1543 1551, 2001.

SULTANA, N.; KEDA, T.; KASHEM, M. A. Effect of seawater on photosynthesis and dry matter accumulation in developing rice grains. Photosynthetica, Prague, v. 40, n. 1, p. 115-119, 2002.

VIEIRA, R. D.; CARVALHO, N. M. Teste de vigor em sementes. Jaboticabal: Funep/Unesp, 1994. 164 p. 